\title{
BMJ Open Consumption and market share of cholesterol-lowering drugs in high-risk patients before and after the release of the 2013 ACC/AHA cholesterol guidelines: a retrospective observational study
}

\author{
Tzu-Tsen Kuo, ${ }^{1,2}$ Yaw-Bin Huang (D) , ${ }^{1}$ Ching-Jung Hsieh (D) ${ }^{3}$
}

To cite: Kuo T-T, Huang YB, Hsieh C-J. Consumption and market share of cholesterol-lowering drugs in high-risk patients before and after the release of the 2013 ACC/AHA cholesterol guidelines: a retrospective observational study. BMJ Open 2020;10:e036769. doi:10.1136/ bmjopen-2020-036769

- Prepublication history and additional materials for this paper is available online. To view these files, please visit the journal online (http://dx.doi org/10.1136/bmjopen-2020036769).

Received 02 January 2020 Revised 19 August 2020 Accepted 20 August 2020
Check for updates

(C) Author(s) (or their employer(s)) 2020. Re-use permitted under CC BY-NC. No commercial re-use. See rights and permissions. Published by BMJ.

For numbered affiliations see end of article.

\section{Correspondence to} Professor Yaw-Bin Huang; yabihu@kmu.edu.tw and Dr Ching-Jung Hsieh; c2607c@ms56.hinet.net

\section{ABSTRACT}

Objective We examined the use of cholesterol-lowering drugs in Taiwan in high-risk patients before and after the release of the 2013 American College of Cardiology and the American Heart Association (ACC/AHA) cholesterol guidelines.

Design Retrospective observational study.

Setting Kaohsiung Chang Gung Memorial Hospital

database, Kaohsiung City, Taiwan.

Participants Outpatients aged $\geq 20$ years with atherosclerosis cardiovascular disease, familial hypercholesterolaemia and diabetes.

Primary and secondary outcome measures Data on brand and generic names, use and dosage of cholesterollowering drugs in 2012 and 2015 were compiled and the total amount used was calculated. Differences in usage and market share were compared. Usage rates of single and fixed-dose combination (FDC) products were compared.

Results The number of patients receiving ambulatory care increased from 36367 in 2012 to 41807 in 2015. Single (3679 979-4568086 tablets) and FDC (540522572954 tablets) product use increased from 2012 to 2015 , respectively. Statins were the most commonly prescribed medications in 2012 (71.14\%) and 2015 (72.91\%). The average monthly consumption of statin among high-risk patients in 2012 was 269948.8 tablets, and it increased significantly to 343975.3 tablets in 2015. The average monthly consumption of pitavastatin was 34113.4 tablets in 2015, which was significantly higher than 0 in 2012. Conversely, the highest decline was observed for fluvastatin use, with the average monthly consumption being 38754.3 tablets in 2015 , which was significantly lower than 45929.8 tablets consumed in 2012. Regarding FDC therapy for cholesterol-lowering drugs, Vytorin (ezetimibe $10 \mathrm{mg}+$ simvastatin $20 \mathrm{mg}$ ) use was the highest among all FDCs in 2015.

Conclusions The 2013 ACC/AHA cholesterol guidelines likely promoted the use of fixed-dose, high-intensity and moderate-intensity monotherapy and FDC therapy statins in high-risk groups, and this was consistent with the use of high-intensity or moderate-intensity statins in the present
Strengths and limitations of this study

Only high-risk patients in the Kaohsiung Chang Gung Memorial Hospital were included as a representative sample of patients.

- Using database records for 2012 and 2015, we extensively analysed practical changes in the usage of cholesterol-lowering drugs among the study participants.

- This study provides data on the changing growth and decline in the use of fixed-dose combinations along with the utilisation of their constituents, which is currently warranted.

- Some important data were excluded; two sets of data from 2012 and four sets of data from 2015 lacked information on age and were therefore excluded from our analysis.

- Patients' out-of-pocket expenses were not considered, as these involved some uncertainties (eg, medications purchased by patients 'out-of-pocket' may not necessarily be intended for themselves).

study. Furthermore, these changes were associated with increased effectiveness and reduced adverse effects.

\section{INTRODUCTION}

In 2013, the American College of Cardiology and the American Heart Association (ACC/ AHA) published guidelines for clinical hypercholesterolaemia treatment, recommending new therapeutic approaches for coronary artery disease (CAD) involving primary and secondary preventions. These guidelines recommend the use of fixed-dose, highintensity and moderate-intensity HMGCR (3hydroxy-3-methylglutaryl-coenzyme-A [CoA] reductase) inhibitors (statins) to decrease cholesterol levels in high-risk patients with CAD. Treatment with moderate-intensity 
statins lowered low-density lipoprotein cholesterol (LDL-C) by approximately $30 \%-50 \%$ and high-intensity statins lowered LDL-C by $\geq 50 \%$. ${ }^{1}$ There were four highrisk groups, selected on the basis of related risk factors. The first group consisted of patients with atherosclerotic cardiovascular disease (ASCVD), defined as acute coronary syndromes, history of myocardial infarction, stable angina, coronary or other arterial revascularisation, stroke, transient ischaemic stroke, or peripheral arterial disease (PAD). All these conditions can lead to atherosclerosis. ${ }^{1}$ The second group consisted of patients with LDL-C level higher than or equal to $190 \mathrm{mg} / \mathrm{dL}$. The third group consisted of patients aged 40-75 years with diabetes mellitus (DM) and LDL-C level of $70-189 \mathrm{mg}$ / dL. The fourth group consisted of patients aged 40-75 years without DM and LDL-C level of $70-189 \mathrm{mg} / \mathrm{dL}$, and those with $<5 \%$ 10-year ASCVD risk. ${ }^{1}$

These guidelines were set in place to appropriately treat high-risk groups, while also reducing the ASCVD risk by increasing high-intensity or high-dose statin use. ${ }^{2}$ Data from the Department of Health and Welfare of Taiwan in 2016 showed that heart disease, cerebrovascular disease, DM, hypertension and renal disease are ranked second, fourth, fifth, eighth and ninth leading causes of death, respectively, with cardiovascular disease accounting for $31.2 \%$ of total mortality. ${ }^{3}$

Data on the direct association between $\mathrm{CAD}$ and hypercholesterolaemia further encourage use of cholesterollowering drugs. Regardless of primary or secondary prevention, a very low LDL-C is associated with a low incidence of coronary heart disease (CHD) events. ${ }^{45}$ In the Cholesterol Treatment Trialists, a decrease in LDL-C of $1 \mathrm{mM}$ reduced CHD risk by $22 \%{ }^{67}$

Use of cholesterol-lowering drugs has significantly increased since the 2013 revision of the guidelines. ${ }^{8-10}$ However, data on this trend in Taiwan have not been published. In November 2013, the ACC/AHA cholesterol guidelines relating to high-risk groups defined the effect of cholesterol treatment in cardiovascular events, but it is unclear how these guidelines influenced different cholesterol-lowering drug use in Taiwan. Thus, we aimed to explore the trend in cholesterol-lowering drug use before and after the release of the ACC/AHA cholesterol guidelines.

\section{METHODS}

\section{Data source}

In this retrospective observational study, data were obtained from the electronic database of Kaohsiung Chang Gung Memorial Hospital for 2012 and 2015. The number of patients using cholesterol-lowering drugs was estimated on the basis of drug consumption rate. The encounter form consisted of patient identification code, diagnostic information indicating the reason for high-risk designation, diagnostic code and drug prescription. Drug information included monthly and annual prescriptions, brand and generic names, dosages, and prescription dates. The electronic database focused on the annual use of drugs in four pharmaceutical drug categories (supplementary table S1) and presented single and fixed-dose combination (FDC) products.

\section{Study population}

Data of individuals with familial hypercholesterolaemia, $\mathrm{DM}, \mathrm{CAD}$, stroke and PAD designated as high-risk patients, who were prescribed cholesterol-lowering drugs, were compiled. The number of patients enrolled was 36367 in 2012 and 41807 in 2015. The inclusion criteria were (1) presence of ASCVD, (2) familial hypercholesterolaemia, (3) DM and (4) aged $\geq 20$ years. Patients with cancer or without medical records were excluded. The remainder comprised patients who received cholesterol-lowering drugs at least once during the study period. Drug information was used to extract distribution data from the electronic database that contained all cholesterol-lowering drug prescription records.

\section{Assessment indicators}

We calculated the total quantity and variety of cholesterollowering drugs used on a monthly basis, and items with the same ingredient were selected to estimate the total monthly amount of each drug dispensed (see online supplemental table S1). We calculated the annual consumption of all cholesterol-lowering drugs by product class. For cholesterol-lowering drug composition data, the frequency of consumption of Vytorin (ezetimibe + simvastatin at either 10 or $20 \mathrm{mg}$ ), Linicor (lovastatin + niacin) and Caduet (amlodipine + atorvastatin) was evaluated. The monthly consumption rate of various individual cholesterol-lowering drugs and FDCs in 2012 and 2015 was calculated. The monthly mean (average monthly consumption of the year) and market share (the percentage of the market for a product or service that a company supplies) of the cholesterol-lowering drugs were calculated and analysed in terms of relative changes between 2012 and 2015. The analysed drug categories were statins, niacin, cholesterol absorption inhibitors and fibrates. Cholesterol-lowering drugs were categorised according to prescription patterns and divided into single or FDC oral cholesterol-lowering drugs (see online supplemental table S1). The drugs were further classified and evaluated according to their respective treatment patterns.

We identified 2398 patients who started statin monotherapy for type $2 \mathrm{DM}$ and who received at least one prescription for statin monotherapy between 1 February 2007 and 9 September 2013; 1633 of these patients were followed up for 1year until 31 December 2015. The patients were prescribed $10 \mathrm{mg}$ atorvastatin, $80 \mathrm{mg}$ fluvastatin XL, $10 \mathrm{mg}$ rosuvastatin, $40 \mathrm{mg}$ atorvastatin, $2 \mathrm{mg}$ pitavastatin, $40 \mathrm{mg}$ simvastatin or Caduet 5/10 (5 $\mathrm{mg}$ amlodipine $+10 \mathrm{mg}$ atorvastatin). The assessment indicators for effectiveness were high-density lipoprotein cholesterol (HDL-C), LDL-C, total cholesterol (TC) and triglyceride levels. Patients were assessed for myopathy, 
Table 1 Age and sex distribution of patients

\begin{tabular}{cllll}
\hline Variable & 2012 & 2015 & $\boldsymbol{F} / \chi^{2}$ & P value \\
\hline $\begin{array}{lllll}\text { Age }, \mathrm{n} \\
(\text { mean } \pm \text { SD) }\end{array}$ & $\begin{array}{l}36367 \\
(69.2 \pm 11.9)\end{array}$ & $\begin{array}{l}41807 \\
(67.2 \pm 11.9)\end{array}$ & 569.9 & $<0.001$ \\
Sex, $\mathrm{n}(\%)$ & & & 4.2 & 0.039 \\
$\quad$ Female & $16824(46.3)$ & $19032(45.5)$ & & \\
\hline Male & $19543(53.7)$ & $22775(54.5)$ & & \\
\hline
\end{tabular}

myalgia, myositis, rhabdomyolysis, cognitive impairment, peripheral neuropathy, headache, and dyspepsia.

\section{Statistical analysis}

Descriptive statistics were applied to calculate the amount and market share of single and FDC cholesterol-lowering drugs and the relative differences in these rates between 2012 and 2015. Student's t-test was used to compare the average monthly cholesterol-lowering drug consumption rate during both years of the study, and the mean $\pm \mathrm{SD}$ of continuous variables was calculated. HDL-C, LDL-C, TC, myopathy, myalgia, myositis, rhabdomyolysis, cognitive impairment, peripheral neuropathy, headache, an dyspepsia awere compared using McNemar's test. All analyses were performed using SPSS V.21. Differences were regarded as statistically significant at $\mathrm{p}<0.05$.

The patients were not involved in the planning, design, recruitment and conduct of the study. The results will be disseminated to the study participants directly (in person). This is an observation study and not a randomised controlled trial.

\section{RESULTS}

The age and sex distribution of the patients are shown in table 1 .
Consumption rate of each class of drug based on cholesterollowering drug treatments for high-risk groups

The average monthly consumption rate of statin, fibrate, cholesterol absorption inhibitor and niacin tablets was significantly higher in 2015 than in 2012 ( $\mathrm{p}=0.011$, $\mathrm{p}=0.001, \mathrm{p}=0.001$ and $\mathrm{p}=0.006$, respectively; table 2). Statins were prescribed more often than all other drugs, accounting for $71.14 \%$ and $72.91 \%$ of the market share in 2012 and 2015, respectively. Overall, cholesterollowering drug use substantially increased in all high-risk groups, with a 1.27-fold increase in statins (see online supplemental figure S1). Although the average statin use increased in 2015, fluvastatin consumption gradually declined. In 2012, niacin was not used, but its market share had increased to $1.06 \%$ in 2015. Cholesterol absorption inhibitors showed the second highest increase during the study period, and the increase in ezetimibe use alone accounted for $18.10 \%$ of the total increase in this drug class (434916 tablets in 2012 and 517186 tablets in 2015). Fibrate consumption showed the third highest increase from 2012 to 2015, accounting for $7.91 \%$ of the total increase in 2015 (878918 tablets in 2012 and 956535 tablets in 2015).

\section{Cholesterol-lowering drug treatment for high-risk groups}

The use of single-ingredient products including atorvastatin, ezetimibe, fenofibrate, pitavastatin, fluvastatin, gemfibrozil, rosuvastatin and simvastatin was analysed (figure 1). The average monthly consumption of cholesterol-lowering drugs, including atorvastatin $(\mathrm{p}<0.001)$, rosuvastatin $(\mathrm{p}<0.001)$, simvastatin $(\mathrm{p}<0.001)$, pitavastatin $(\mathrm{p}<0.001)$, fluvastatin $(\mathrm{p}<0.001)$, ezetimibe $(\mathrm{p}=0.003)$, fenofibrate $(\mathrm{p}=0.022)$ and gemfibrozil $(0.011)$, in high-risk groups was significantly different between 2015 and 2012 (table 2). Rosuvastatin and atorvastatin accounted for the highest consumption rates among all

Table 2 Monthly quantity and market share of cholesterol-lowering drug classes in 2012 and 2015

\begin{tabular}{lccc}
\hline Mean monthly quantity and market share & 2012 & 2015 & P value \\
\hline HMG-CoA reductase inhibitors, tablets/month (\%) & $269948.8 \pm 19340.3(71.14)$ & $343975.3 \pm 34612.5(72.91)$ & $<0.001$ \\
\hline Fibrates, tablets/month (\%) & $73243.2 \pm 4972.8(19.30)$ & $79711.3 \pm 6391.4(16.89)$ & 0.011 \\
\hline Cholesterol absorption inhibitors, tablets/month (\%) & $36243.0 \pm 3644.9(9.55)$ & $43098.8 \pm 5095.6(9.13)$ & 0.001 \\
\hline Niacin, tablets/month (\%) & - & $5024.0 \pm 5162.0(1.06)$ & 0.006 \\
Atorvastatin, tablets/month (\%) & $68032.3 \pm 4772.6(22.18)$ & $84406.8 \pm 7321.5(22.17)$ & $<0.001$ \\
\hline Rosuvastatin, tablets/month (\%) & $94952.6 \pm 6657.1(30.96)$ & $121829.9 \pm 9972.9(32.00)$ & $<0.001$ \\
Simvastatin, tablets/month (\%) & $15990.6 \pm 1301.6(5.21)$ & $12100.8 \pm 1120.0(3.18)$ & $<0.001$ \\
\hline Pitavastatin, tablets/month (\%) & - & $34113.4 \pm 7507.4(8.96)$ & $<0.001$ \\
\hline Fluvastatin, tablets/month (\%) & $45929.8 \pm 3298.2(14.98)$ & $38754.3 \pm 2844.0(10.18)$ & $<0.001$ \\
\hline Ezetimibe, tablets/month (\%) & $8516.4 \pm 636.8(2.78)$ & $9757.5 \pm 1095.6(2.56)$ & 0.003 \\
\hline Fenofibrate, tablets/month (\%) & $38069.8 \pm 2429.4(12.41)$ & $40854.9 \pm 3085.2(10.73)$ & 0.022 \\
\hline Gemfibrozil, tablets/month (\%) & $35173.3 \pm 3056.0(11.47)$ & $38856.3 \pm 3437.9(10.21)$ & 0.011 \\
\hline
\end{tabular}

Mean \pm SD represents the number of patients receiving a particular cholesterol-lowering drug in 1 month.

HMG-CoA, 3-hydroxy-3-methylglutaryl- coenzyme-A. 


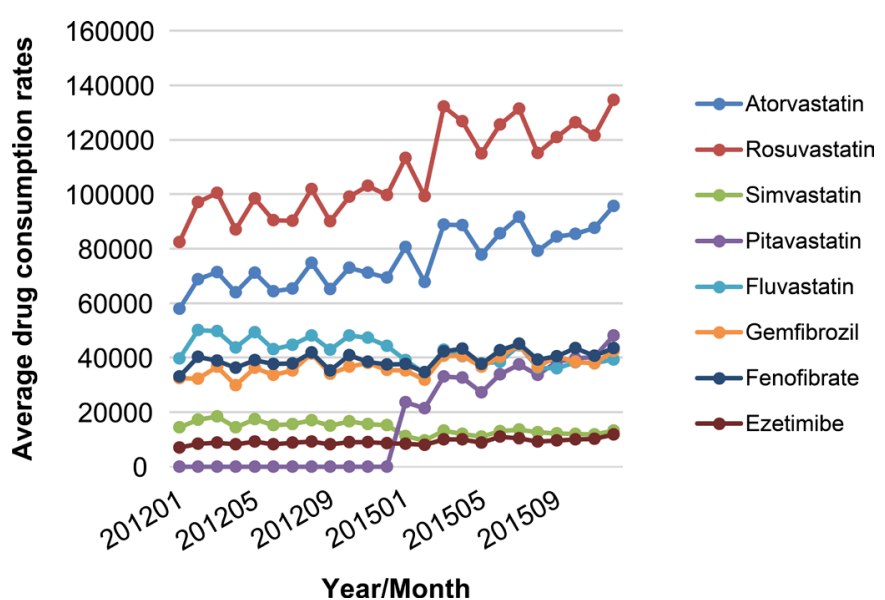

Figure 1 Monthly use of individual cholesterol-lowering drugs in 2012 and 2015. Use of pitavastatin, rosuvastatin and atorvastatin increased between 2012 and 2015. Fluvastatin use declined and accounted for only $14.98 \%$ and $10.18 \%$ of all single cholesterol-lowering drugs in 2012 and 2015, respectively.

the studied drugs in 2015 ( $>1$ million tablets or capsules) (rosuvastatin: 1461959 tablets; atorvastatin: 1012881 tablets). The use of all these drugs increased except that of fluvastatin and simvastatin, which was significantly lower in 2015 than in 2012 ( $\mathrm{p}<0.001$ each; simvastatin: 15990.6 tablets in 2012 and 12100.8 tablets in 2015; fluvastatin: 45929.8 tablets in 2012 and 38754.3 tablets in 2015). However, the percentage of market shares of all drugs decreased during this period, except for rosuvastatin and pitavastatin.

The use of rosuvastatin $10 \mathrm{mg}$ (2531345 tablets) was 36.1 times higher than that of rosuvastatin $5 \mathrm{mg}$ ( 70045 tablets). Its therapeutic doses were classified as high intensity $(20-40 \mathrm{mg})$ and moderate intensity $(5-10 \mathrm{mg})$. Atorvastatin $10 \mathrm{mg}$ use increased by nearly two times that of atorvastatin $40 \mathrm{mg}$. The consumption of simvastatin $40 \mathrm{mg}$ decreased from 191887 tablets in 2012 to 145209 tablets in 2015 as its market share dropped from $5.21 \%$ to $3.18 \%$, respectively. Conversely, ezetimibe $10 \mathrm{mg}$ use increased as its market share dropped from $2.78 \%$ to $2.56 \%$. In 2012 , rosuvastatin (1139431 tablets), atorvastatin (816388 tablets) and fluvastatin (551 158 tablets) were consumed at the highest rates. By 2015, the three most highly used drugs were rosuvastatin (1461959 tablets), atorvastatin (1012881) and fenofibrate (490259). Similar to atorvastatin use, rosuvastatin use was high in 2012 (1139431 tablets), and it increased further in 2015 (1461959). Pitavastatin use increased the most, possibly because it had just been added after the release of the revised ACC/ AHA guidelines. Moreover, data on pitavastatin use in 2012 were not available.

\section{Cholesterol-lowering FDC treatments for high-risk groups}

In 2012 and 2015, the main FDCs used were Linicor, Vytorin (ezetimibe $10 \mathrm{mg}+$ simvastatin $10 \mathrm{mg}$, ezetimibe $10 \mathrm{mg}+$ simvastatin $20 \mathrm{mg}$ ) and Caduet. Table 3 shows the monthly average FDC use and their market shares. The usage rate of Vytorin (ezetimibe $10 \mathrm{mg}+$ simvastatin $10 \mathrm{mg}$ ) and Caduet in 2015 was significantly lower than that in 2012 ( $p=0.001$; table 3$)$. FDCs accounted for $12.81 \%$ of all cholesterol-lowering drugs used in 2012 and $12.17 \%$ in 2015. In 2012, Linicor was not prescribed, and its market share was $9.52 \%$ in 2015 . In 2012, the market shares of Vytorin (ezetimibe $10 \mathrm{mg}+$ simvastatin $10 \mathrm{mg}$ ) and Caduet were $1.31 \%$ and $38.44 \%$, respectively, which were higher than $0.48 \%$ and $27.30 \%$ in 2015 , respectively. The consumption of the FDC amlodipine $5 \mathrm{mg}+$ atorvastatin $10 \mathrm{mg}$ decreased as its market share dropped from $38.44 \%$ to $27.30 \%$, and it affected the usage of the individual constituents. Although use of atorvastatin 10 $\mathrm{mg}$ and $40 \mathrm{mg}$ increased, their market shares slightly decreased from $22.18 \%$ to $22.17 \%$.

Consumption of the FDC ezetimibe $10 \mathrm{mg}+$ simvastatin $10 \mathrm{mg}$ decreased as its market share dropped from $1.31 \%$ to $0.48 \%$. In contrast, in 2012 , the market shares of Linicor and Vytorin (ezetimibe $10 \mathrm{mg}+$ simvastatin $20 \mathrm{mg}$ ) were $0 \%$ and $60.24 \%$, respectively, which were lower than $9.52 \%$ and $62.71 \%$ in 2015 , respectively. Linicor use was ranked third among FDCs, yielding a market share of $9.52 \%$.

In our data set, niacin use showed the least increase, as Linicor was unavailable in the study hospital before 2015. The consumption of ezetimibe $10 \mathrm{mg}$ and simvastatin $10 \mathrm{mg}$ declined more than that of the other FDCs. However, ezetimibe $10 \mathrm{mg}$ and simvastatin $20 \mathrm{mg}$ are suitable for high-intensity use in high-risk groups. Therefore, their consumption has gradually increased (figure 2).

\begin{tabular}{|c|c|c|c|}
\hline Drug & 2012 & 2015 & $P$ value \\
\hline $\begin{array}{l}\text { Linicor (lovastatin } 20 \mathrm{mg}+\text { niacin ER } 500 \mathrm{mg} \text { )/tablet, tablets/ } \\
\text { month (\%) }\end{array}$ & - & $5024.0 \pm 5162.0(9.52)$ & 0.006 \\
\hline $\begin{array}{l}\text { Vytorin (ezetimibe } 10 \mathrm{mg}+\text { simvastatin } 10 \mathrm{mg} \text { )/tablet, tablets/ } \\
\text { month (\%) }\end{array}$ & $590.6 \pm 111.0(1.31)$ & $251.3 \pm 77.0(0.48)$ & $<0.001$ \\
\hline $\begin{array}{l}\text { Vytorin (ezetimibe } 10 \mathrm{mg}+\text { simvastatin } 20 \mathrm{mg} \text { )/tablet, tablets/ } \\
\text { month (\%) }\end{array}$ & $27136.0 \pm 3047.0(60.24)$ & $33090.0 \pm 4139.0(62.71)$ & 0.001 \\
\hline $\begin{array}{l}\text { Caduet } 5 / 10 \text { (amlodipine } 5 \mathrm{mg}+\text { atorvastatin } 10 \mathrm{mg} \text { )/tablet, } \\
\text { tablets/month (\%) }\end{array}$ & $17316.9 \pm 2349.2(38.44)$ & $14404.8 \pm 1228.9(27.30)$ & 0.001 \\
\hline
\end{tabular}

Mean \pm SD represents the number of patients receiving a given drug each year. 


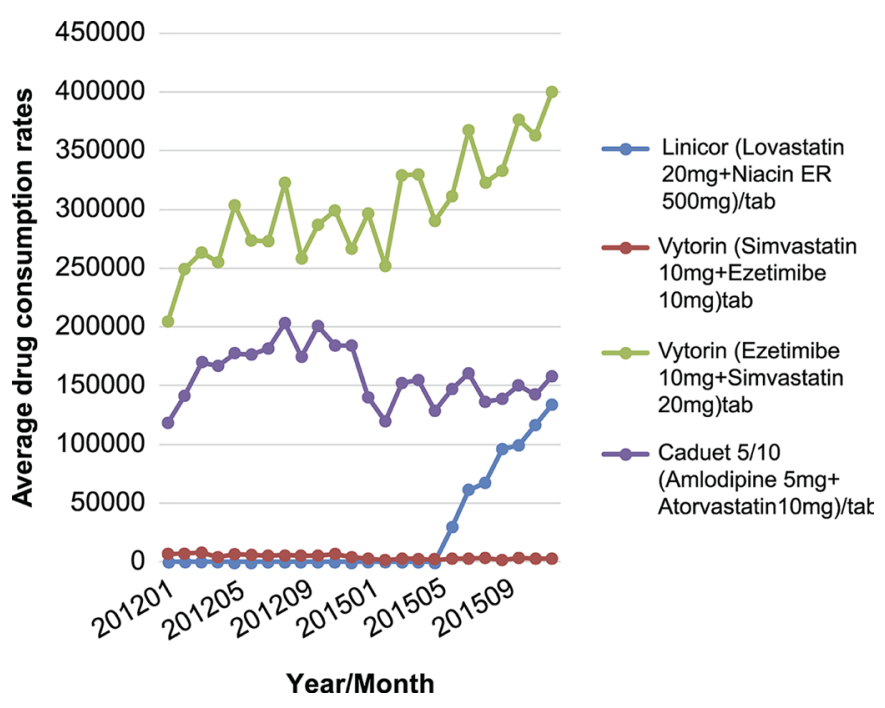

Figure 2 Fixed-dose combination (FDC) cholesterollowering drugs consumed monthly in 2012 and 2015. Vytorin (ezetimibe $10 \mathrm{mg}+$ simvastatin $20 \mathrm{mg}$ ) use increased from 2012 to 2015, with the highest FDC share at 62.71\% in 2015. Linicor (lovastatin $20 \mathrm{mg}$ + niacin ER $500 \mathrm{mg}$ ) usage also increased, and it was the second most widely used FDC. By 2015 , it accounted for $9.52 \%$ of all FDCs consumed. Use of Caduet (amlodipine $5 \mathrm{mg}+$ atorvastatin $10 \mathrm{mg}$ ) declined between 2012 and 2015.

Vytorin (ezetimibe $10 \mathrm{mg}+$ simvastatin $20 \mathrm{mg}$ ) use was the highest of all FDCs in 2015. The consumption of simvastatin $10 \mathrm{mg}$ in FDC has declined, whereas that of simvastatin $20 \mathrm{mg}$ has increased ${ }^{6}$ (ezetimibe $10 \mathrm{mg}+$ simvastatin $10 \mathrm{mg}$ : 590.6 tablets in 2012 and 251.3 tablets in 2015; ezetimibe $10 \mathrm{mg}+$ simvastatin $20 \mathrm{mg}$ : 27136.0 tablets in 2012 and 33090.0 in 2015).

Collectively, the overall consumption of these three FDCs increased, which affected the use of their individual constituents. The introduction of the aforementioned FDCs in the study hospital affected the consumption rate of both their individual constituents and the other FDCs. The FDCs ezetimibe $10 \mathrm{mg}+$ simvastatin $10 \mathrm{mg}$ and ezetimibe $10 \mathrm{mg}+$ simvastatin $20 \mathrm{mg}$ were introduced on 9 March 2007 and 30 December 2008, respectively, whereas simvastatin $40 \mathrm{mg}$, ezetimibe $10 \mathrm{mg}$ and atorvastatin $10 \mathrm{mg}$ were introduced on 4 November 2004, 22 March 2006 and 22 February 2001, respectively. The consumption of ezetimibe $10 \mathrm{mg}+$ simvastatin $20 \mathrm{mg}$ increased as its market share increased from $60.24 \%$ to $62.71 \%$. The introduction of the FDC lovastatin $20 \mathrm{mg}+$ niacin ER $500 \mathrm{mg}$ led to a decrease in the use of the FDC amlodipine $5 \mathrm{mg}+$ atorvastatin $10 \mathrm{mg}$ (lovastatin $20 \mathrm{mg}$ + niacin ER $500 \mathrm{mg}$ : 0 tablets in 2012 and 5024.0 tablets in 2015; amlodipine $5 \mathrm{mg}+$ atorvastatin $10 \mathrm{mg}$ : 17316.9 tablets in 2012 and 14404.8 tablets in 2015) with a reduction in its market share from $38.44 \%$ to $27.30 \%$. Although the consumption of simvastatin $40 \mathrm{mg}$ decreased as its market share dropped from $5.21 \%$ to $3.18 \%$ (15990.6 tablets in 2012 and 12100.8 in 2015), ezetimibe $10 \mathrm{mg}$ use increased, although its market share dropped from $2.78 \%$ to $2.56 \%$ (8516.4 tablets in 2012 and 9757.5 in 2015).
Effectiveness and adverse effects before and after treatment with statins for 1 and 2 years in patients with diabetes

In terms of effectiveness, HDL-C, LDL-C, TC and triglyceride levels in the 2398 patients treated with statins for a year showed significant improvements (all $\mathrm{p}<0.001$ ). The probability of myalgia, myositis, rhabdomyolysis, peripheral neuropathy, headache and dyspepsia was not significant. The incidence of myopathy and cognitive impairment was 0 .

Significant improvements in HDL-C, LDL-C, TC and triglyceride levels were observed in the 1633 patients treated with statin for 2 years (all $\mathrm{p}<0.001)$. These patients also showed a significant probability of myalgia $(\mathrm{p}=0.004)$ and myositis $(\mathrm{p}=0.004)$ whereas the probability of rhabdomyolysis $(\mathrm{p}=1.000)$, peripheral neuropathy $(\mathrm{p}=1.000)$, headache $(\mathrm{p}=0.581)$ and dyspepsia $(\mathrm{p}=0.500)$ was not significant. The incidence of myopathy and cognitive impairment was 0 .

Regarding effectiveness, the probability of HDL-C $(p=0.016)$, LDL-C $(p<0.001)$ and TC $(p=0.027)$ levels in the 1633 patients treated continuously with statin for 1 year was significant. Changes in triglyceride level in the 1633 patients treated continuously with statin for 1 year were not significant $(\mathrm{p}=0.576)$.

Regarding adverse effects, the resultant changes in myalgia and myositis were significant (each $\mathrm{p}=0.008$ ). The resultant probability of rhabdomyolysis, peripheral neuropathy, headache and dyspepsia $(\mathrm{p}=1.000)$ was not significant. The incidence of myopathy and cognitive impairment was 0 .

\section{DISCUSSION}

The 2013 ACC/AHA cholesterol guidelines most strongly affected patients 40-75 years of age who did not accept baseline treatments, but began receiving statins for primary ASCVD prevention. Although patients received statins at baseline (LDL-C $<80$ or $<150 \mathrm{mg} / \mathrm{dL}$ ), their relative risk reductions remained the same. ${ }^{11}$ Taiwan followed the recommendations in the 2013 ACC/AHA cholesterol guidelines in treating patients with LDL-C level of $\geq 100 \mathrm{mg} / \mathrm{dL}$. This is primarily owing to the refusal of the National Health Insurance to approve treatments for patients with LDL-C level below $100 \mathrm{mg} / \mathrm{dL}$, unless they have a cardiovascular disease or diabetes. The contribution of the National Health Insurance to cholesterollowering drugs was eventually broadened to include patients with cardiovascular disease or diabetes and put into effect on 1 August 2013. However, in the past, drug treatment was contingent on a TC level of $\geq 200 \mathrm{mg} / \mathrm{dL}$ or an LDL-C level of $\geq 130 \mathrm{mg} / \mathrm{dL}$. Currently, patients with $\mathrm{TC} \geq 160 \mathrm{mg} / \mathrm{dL}$ or LDL-C $\geq 100 \mathrm{mg} / \mathrm{dL}$ can receive treatments. Physicians can also evaluate the conditions of patients to decide if drug cessation is appropriate. ${ }^{12}$

Although the market share of niacin has increased, the market shares of the other drug classes have decreased, suggesting that cholesterol-lowering drug consumption is not as consistent as previously reported. ${ }^{9}$ Tran $e t$ 
$a l^{9}$ found a $25 \%$ overall increase in statin use in 2014 and a $68 \%$ decline in the consumption of non-statin cholesterol-lowering drugs. However, their methodology differed from ours in using OptumRx pharmacy notices for baseline values to determine the number of patients who could start or switch to statin therapy according to the 2013 ACC/AHA cholesterol treatment guidelines. Because the timeframe of 1 January-31 December 2013 is the newly released 2013 ACC/AHA cholesterol treatment guide, there was no buffer period. ${ }^{13}$

The administration of cholesterol absorption inhibitors showed the second highest increase. The lack of definitive cardiovascular benefit had previously limited the widespread adoption of ezetimibe ${ }^{13}$ However, patients with genetic mutations such as Niemann-Pick C1 like 1 (NPC1L1) and HMGCR are especially affected by ezetimibe use in terms of LDL-C and cardiovascular risk reduction. As a considerable proportion of the Taiwanese population carry these mutations, ezetimibe is likely to be of use in this region. Fibrate use in the treatment of dyslipidaemia has significantly changed recently. ${ }^{14}$ Fibrate use showed the third highest increase from 2012 to 2015.

Trials of niacin and fibrate reported no significant reduction in cardiovascular events. ${ }^{15}$ In our data set, the increase in niacin use was the least. The data reported by Tran $e t a t^{\theta}$ were inconsistent with these findings.

We found that following the release of the 2013 ACC/ AHA cholesterol guidelines, there was a significant decrease in use of simvastatin and fluvastatin and an increase in use of other statins. Rosuvastatin and atorvastatin may account for the highest consumption rates among all studied drugs in 2015 ( $>1$ million tablets or capsules). In 2012, the consumption rate of rosuvastatin, atorvastatin and fluvastatin was the highest among all cholesterol-lowering drugs, but by 2015 the three most highly used drugs were rosuvastatin, atorvastatin and fenofibrate. Atorvastatin presented the second highest consumption rate, although its market share decreased between 2012 and 2015. The branded and generic forms of atorvastatin became available on 1 October 1997 and 18 July 2010, respectively, whereas generic rosuvastatin appeared in the market on 9 April 2012. Because the expiry of the best-selling drug patent is an important driving force for the growth of the generic drug market, it results in increased generic product use. This may explain the observed increase in atorvastatin and rosuvastatin use. Atorvastatin $10 \mathrm{mg}$ (which is considered a moderate dose when prescribed by physicians) ${ }^{16}$ use was two times higher than atorvastatin $40 \mathrm{mg}$ use. Renal clearance is generally lower for atorvastatin, making it a better choice for renal dysfunction. ${ }^{17}$ Atorvastatin in primary prevention is related to LDL-C, which has a similar extent of effect in global and Asian populations, and it may be advisable to use it at low doses. ${ }^{18-21}$

Similar to atorvastatin, rosuvastatin use was high in 2012 and increased further by 2015. The rosuvastatin level in plasma is significantly higher in Asians than in Caucasians; therefore, rosuvastatin dosage often differs slightly between these populations. ${ }^{22}$ This may explain why the use of rosuvastatin $10 \mathrm{mg}$ was greater than that of rosuvastatin $5 \mathrm{mg}$. Here, pitavastatin usage increased the most, at least partially because it had recently been added to the hospital after the release of the revised ACC/ AHA guidelines. In the study hospital, pitavastatin $2 \mathrm{mg}$ tablets (Livalo) have been prescribed since 5 July 2013, while Pitator has been administered since 7 November 2014. Although pitavastatin is the newest member of the HMGCR inhibitor family, there were no significant differences in the favourable effects on lipid parameters between pitavastatin and atorvastatin. However, pitavastatin has been associated with increased HDL-C level. ${ }^{23}$

Pitavastatin undergoes minimal metabolism by the cytochrome P450 (CYP) enzymes. Therefore, it has a low propensity for interaction with drugs metabolised by the CYP enzymes. ${ }^{23}$ Thus, it provides a clear benefit for patients administered multiple drugs simultaneously. ${ }^{24}$ Unlike other statins in this study, single simvastatin $40 \mathrm{mg}$ pill use rapidly decreased.

Simvastatin consumption was considerably lower in 2015, possibly due to its recognised risk for myopathy and rhabdomyolysis. ${ }^{25}$ Fluvastatin consumption also considerably decreased, possibly because it is a low-intensity and short-acting statin with poorer performance than other options.

Similar to statins, fibrate consumption also increased with time, with fenofibrate and gemfibrozil ranked the fifth and fourth most highly consumed cholesterollowering drugs, respectively. Fibrates may be combined with statins to treat mixed dyslipidaemia. ${ }^{26}$ Fenofibrate interacts with statins more effectively than gemfibrozil. ${ }^{27}$ The latter is associated with a relatively higher risk of inducing rhabdomyolysis. ${ }^{28}$

Cholesterol-lowering drugs used in FDC were simvastatin $10 \mathrm{mg}$ with ezetimibe $10 \mathrm{mg}$, simvastatin $20 \mathrm{mg}$ with ezetimibe $10 \mathrm{mg}$, and atorvastatin $10 \mathrm{mg}$ with amlodipine $5 \mathrm{mg}$. The consumption of ezetimibe $10 \mathrm{mg}$ and simvastatin $10 \mathrm{mg}$ declined more than the other FDCs. The consumption of simvastatin $10 \mathrm{mg}$ in FDC has declined, whereas that of simvastatin $20 \mathrm{mg}$ has increased. ${ }^{6}$ Ezetimibe $10 \mathrm{mg}$ and simvastatin $20 \mathrm{mg}$ are suitable for highintensity use in high-risk groups. ${ }^{29}$ These drugs lower the LDL-C level more effectively in combination than as monotherapy. ${ }^{30}$ However, when ezetimibe is combined with simvastatin, the cost may increase. Therefore, it is easy to cross the $50 \%$ LDL-C threshold to meet this standard ${ }^{32}$ Linicor use was ranked third among FDCs. Linicor is a single-pill combination of lovastatin and niacin which reduces LDL-C, increases HDL-C and improves mixed dyslipidaemia, with fewer adverse effects than immediaterelease niacin. ${ }^{334}$ However, compared with high-intensity drugs, its effect in decreasing LDL-C is poor. Nonetheless, it is cost-effective for patients in Taiwan with health insurance, as it is available at only $\$ 10.90$ per capsule, which may explain its increased usage.

Although lovastatin is not administered alone because of its short half-life in blood circulation, it cannot be 
strictly defined as FDC because the other components enhance the efficacy of the active ingredient. ${ }^{35}$ In 2015 , the drug held a market share of $9.52 \%$. The introduction of the FDC lovastatin $20 \mathrm{mg}+$ niacin ER $500 \mathrm{mg}$ led to a decrease in the use of the FDC amlodipine $5 \mathrm{mg}+$ atorvastatin $10 \mathrm{mg}$ and reduced its market share from $38.44 \%$ to $27.30 \%$. The FDC lovastatin $20 \mathrm{mg}+$ niacin ER $500 \mathrm{mg}$ is particularly useful for patients who must increase their HDL-C and reduce LDL-C level. Niacin is a B-complex vitamin that affects multiple lipoproteins and is currently the most effective drug for increasing HDL-C level ${ }^{36}$ Niacin lowers lipoprotein (s) by $\leq 25 \%$ and is effective for patients with combined hyperlipidaemia and low HDL-C level. Lovastatin $20 \mathrm{mg}+$ niacin ER $500 \mathrm{mg}$ is not prescribed or administered individually, which may account for the increase in the use of this particular FDC.

The overall consumption of the analysed FDCs increased, which affected the use of their individual constituents. Although the consumption of simvastatin $40 \mathrm{mg}$ decreased as its market share dropped, ezetimibe $10 \mathrm{mg}$ use increased despite a drop in its market share. The combination of ezetimibe with a statin may reduce LDL-C by $\geq 20 \%$, lower triglycerides by $7 \%-13 \%$ and increase HDL-C by $1 \%-5 \%$. These effects increase with statin dose. The ease of administration of statin-ezetimibe combinations and the minimal incidence of associated adverse effects render them efficacious in substantially lowering LDL-C level.

Similar to statins, the usage rate of both single and FDC cholesterol-lowering products increased in 2015. Statins supplemented with ezetimibe are highly effective in improving blood lipid profiles. ${ }^{37}$ However, in Taiwan, the National Health Insurance regulations do not require the reduction or discontinuation of these drugs after the treatment target has been attained. Physicians may appropriately manage patients' conditions and integrate lifelong disease prevention in the treatment regimen. Lifelong disease prevention is crucial in therapeutic management, and the International Atherosclerosis Society recommends that lipid-lowering therapies include long-term extrapolation of the risk of a cardiovascular event by 80 years of age.$^{38}$ Determination of the risk factors of cardiovascular disease in apparently healthy individuals and extension of the scope of treatment to primary prevention have critical implications for public health.

Our study had some limitations. (1) Some important data were excluded; two sets of data from 2012 and four sets of data from 2015 lacked information on age and were therefore excluded from our analysis. (2) Patients' out-of-pocket expenses were not considered, as these involved some uncertainties (eg, medications purchased by patients 'out-of-pocket' may not necessarily be intended for themselves). (3) The guidelines recommended changes in cholesterol treatment. However, some of the new guidelines imposed unknown restrictions for doctors; there were also restrictions on patient adherence to the guidelines.

\section{CONCLUSIONS}

Overall, our results show the increased use of fixed-dose, high-intensity and moderate-intensity monotherapy and combined therapy statins in high-risk groups, which matches the recommendations of the 2013 ACC/AHA guidelines. These changes were associated with increased effectiveness and reduced adverse effects to have an effect on patients.

\section{Author affiliations}

${ }^{1}$ School of Pharmacy, Kaohsiung Medical University, Kaohsiung, Taiwan 2Department of Pharmacy, Kaohsiung Chang Gung Memorial Hospital, Kaohsiung, Taiwan

${ }^{3}$ Division of Endocrinology and Metabolism, Department of Internal Medicine, Pao Chien Hospital, Pingtung, Taiwan

Correction notice This article has been corrected since it was first published. Ching-Jung Hsieh has been listed as the second corresponding author.

Acknowledgements The authors thank the staff of Kaohsiung Chang Gung Memorial Hospital, Taiwan for their assistance with data collection.

Contributors T-TK analysed and interpreted the data and wrote the manuscript. Y-BH and C-JH acquired the data, contributed to the discussion and critically revised the manuscript. T-TK was the guarantor of the present study and verified the accuracy and integrity of all research-related information.

Funding The authors have not declared a specific grant for this research from any funding agency in the public, commercial or not-for-profit sectors.

Competing interests None declared.

Patient consent for publication Not required.

Ethics approval The study design was approved by the Institutional Review Board of Chang Gung Medical Foundation, Kaohsiung, Taiwan (no. 201700290B0).

Provenance and peer review Not commissioned; externally peer reviewed. Data availability statement Data are available upon reasonable request.

Open access This is an open access article distributed in accordance with the Creative Commons Attribution Non Commercial (CC BY-NC 4.0) license, which permits others to distribute, remix, adapt, build upon this work non-commercially, and license their derivative works on different terms, provided the original work is properly cited, appropriate credit is given, any changes made indicated, and the use is non-commercial. See: http://creativecommons.org/licenses/by-nc/4.0/.

\section{ORCID iDs}

Yaw-Bin Huang http://orcid.org/0000-0002-6024-0108

Ching-Jung Hsieh http://orcid.org/0000-0001-9950-9269

\section{REFERENCES}

1 Stone NJ, Robinson JG, Lichtenstein AH, et al. ACC/AHA guideline on the treatment of blood cholesterol to reduce atherosclerotic cardiovascular risk in adults: a report of the American College of Cardiology/American heart association Task force on practice guidelines. J Am Coll Cardiol 2013;2014:2889-934.

2 Stone NJ, Robinson JG, Lichtenstein AH, et al. ACC/AHA guideline on the treatment of blood cholesterol to reduce atherosclerotic cardiovascular risk in adults: a report of the American college of cardiology/American heart association Task force on practice guidelines. Circulation 2013;2014:S1-45.

3 Department of Statistics, Ministry of Health and Welfare. Taiwan's leading causes of death in 2016. Available: https://www.mohw.gov. tw/cp-115-33347-2.html [Accessed 26 Mar 2019].

4 LaRosa JC, Grundy SM, Waters DD, et al. Intensive lipid lowering with atorvastatin in patients with stable coronary disease. $N$ Engl J Med 2005;352:1425-35.

5 Rosenson RS. Statins: can the new generation make an impression? Expert Opin Emerg Drugs 2004;9:269-79.

6 Cannon CP, Blazing MA, Giugliano RP, et al. Ezetimibe added to statin therapy after acute coronary syndromes. $N$ Engl J Med 2015;372:2387-97. 
7 Cholesterol Treatment Trialists' (CTT) Collaboration, Baigent C, Blackwell L, et al. Efficacy and safety of more intensive lowering of LDL cholesterol: a meta-analysis of data from 170,000 participants in 26 randomised trials. Lancet 2010;376:1670-81.

8 Steen DL, Khan I, Becker L, et al. Patterns and predictors of lipidlowering therapy in patients with atherosclerotic cardiovascular disease and/or diabetes mellitus in 2014: insights from a large US managed-care population. Clin Cardiol 2017;40:155-62.

9 Tran JN, Caglar T, Stockl KM, et al. Impact of the new ACC/AHA guidelines on the treatment of high blood cholesterol in a managed care setting. Am Heal drug benefits 2014;7:430-43.

10 Rosenson RS, Farkouh ME, Mefford M, et al. Trends in use of highintensity statin therapy after myocardial infarction, 2011 to 2014 . J Am Coll Cardiol 2017;69:2696-706.

11 Cholesterol Treatment Trialists' (CTT) Collaborators, Mihaylova B, Emberson J, et al. The effects of lowering LDL cholesterol with statin therapy in people at low risk of vascular disease: metaanalysis of individual data from 27 randomised trials. Lancet 2012;380:581-90.

12 Central Health Insurance Agency, Ministry of Health and Welfare. Announcement on revised lipid-lowering drug payment regulations. Available: http://www.nhi.gov.tw/epaper/ltemDetail.aspx?DatalD= 3364\&IsWebData=0\&ltemTypelD=2\&Papers ID=293\&PiclD [Accessed 26 Mar 2019].

13 Sisson EM, Pamulapati L, Bucheit JD, et al. Evolving role of non-statin therapy for the management of dyslipidemia and cardiovascular risk reduction: past, present, and future. Pharmacotherapy 2018;38:164-71.

14 Shipman KE, Strange RC, Ramachandran S. Use of fibrates in the metabolic syndrome: a review. World J Diabetes 2016;7:74-88.

15 Lloyd-Jones DM, Morris PB, Ballantyne CM, et al. Acc expert consensus decision pathway on the role of Non-Statin therapies for LDL-cholesterol lowering in the management of atherosclerotic cardiovascular disease risk: a report of the American College of cardiology Task force on clinical expert consensus documents. J Am Coll Cardiol 2016;2016:92-125.

16 Hsieh H-C, Hsu JC, Lu CY. 10-year trends in statin utilization in Taiwan: a retrospective study using Taiwan's National health insurance research database. BMJ Open 2017;7:e014150.

17 European Association for Cardiovascular Prevention \& Rehabilitation, Reiner Z, Catapano AL, et al. ESC/EAS guidelines for the management of dyslipidaemias: the task force for the management of dyslipidaemias of the European Society of cardiology (ESC) and the European atherosclerosis Society (EAS). Eur Heart $J$ 2011;32:1769-818.

18 Sever PS, Dahlöf B, Poulter NR, et al. Prevention of coronary and stroke events with atorvastatin in hypertensive patients who have average or lower-than-average cholesterol concentrations, in the anglo-scandinavian cardiac outcomes trial-lipid lowering arm (ASCOT-LLA): a multicentre randomised controlled trial. Lancet 2003;361:1149-58

19 Sever PS, Poulter NR, Dahlöf B, et al. Reduction in cardiovascular events with atorvastatin in 2,532 patients with type 2 diabetes: Anglo-Scandinavian Cardiac Outcomes Trial-lipid-lowering arm (ASCOT-LLA). Diabetes Care 2005;28:1151-7.
20 Recto CS, Acosta S, Dobs A. Comparison of the efficacy and tolerability of simvastatin and atorvastatin in the treatment of hypercholesterolemia. Clin Cardiol 2000;23:682-8.

21 Wu C-C, Sy R, Tanphaichitr V, et al. Comparing the efficacy and safety of atorvastatin and simvastatin in Asians with elevated lowdensity lipoprotein-cholesterol-a multinational, multicenter, doubleblind study. J Formos Med Assoc 2002;101:478-87.

22 Lee E, Ryan S, Birmingham B, et al. Rosuvastatin pharmacokinetics and pharmacogenetics in white and Asian subjects residing in the same environment. Clin Pharmacol Ther 2005;78:330-41.

23 da Silva PM. Are all statins the same? focus on the efficacy and tolerability of pitavastatin. Am J Cardiovasc Drugs 2011;11:93-107.

24 Masana L. Pitavastatin - from clinical trials to clinical practice. Atheroscler Suppl 2010;11:15-22.

25 Talreja O, Kerndt C, Cassagnol M. Simvastatin. Treasure Island, FL, 2020.

26 Fiévet C, Staels B. Combination therapy of statins and fibrates in the management of cardiovascular risk. Curr Opin Lipidol 2009;20:505-11.

27 Jacobson TA, Zimmerman FH. Fibrates in combination with statins in the management of dyslipidemia. J Clin Hypertens 2006;8:35-41.

28 Xavier HT. [Drug combinations: statins and fibrates]. Arq Bras Cardiol 2005;85:34-5.

29 Hou R, Goldberg AC. Lowering low-density lipoprotein cholesterol: statins, ezetimibe, bile acid sequestrants, and combinations: comparative efficacy and safety. Endocrinol Metab Clin North Am 2009;38:79-97.

30 Cohen DE. Balancing cholesterol synthesis and absorption in the gastrointestinal tract. J Clin Lipidol 2008;2:S1-3.

31 Grigore L, Norata GD, Catapano AL. Combination therapy in cholesterol reduction: focus on ezetimibe and statins. Vasc Health Risk Manag 2008;4:267-78.

32 Jones PH, Davidson MH, Stein EA, et al. Comparison of the efficacy and safety of rosuvastatin versus atorvastatin, simvastatin, and pravastatin across doses (STELLAR ${ }^{\star}$ trial). Am J Cardiol 2003;92:152-60.

33 Insull W, McGovern ME, Schrott H, et al. Efficacy of extendedrelease niacin with lovastatin for hypercholesterolemia: assessing all reasonable doses with innovative surface graph analysis. Arch Intern Med 2004;164:1121-7.

34 Kurogi K, Sugiyama S, Sakamoto K, et al. Comparison of pitavastatin with atorvastatin in increasing $\mathrm{HDL}$-cholesterol and adiponectin in patients with dyslipidemia and coronary artery disease: the COMPACT-CAD study. J Cardiol 2013;62:87-94.

35 Klimek M, Wang S, Ogunkanmi A. Safety and efficacy of red yeast rice (Monascus purpureus) as an alternative therapy for hyperlipidemia. P T 2009;34:313-27.

36 Crouse JR. New developments in the use of niacin for treatment of hyperlipidemia: new considerations in the use of an old drug. Coron Artery Dis 1996;7:321-6.

37 Farrer S. Beyond statins: emerging evidence for hdl-increasing therapies and diet in treating cardiovascular disease. Adv Prev Med 2018;2018:1-9.

38 Hamilton-Craig I, Colquhoun D, Kostner K, et al. Lipid-modifying therapy in the elderly. Vasc Health Risk Manag 2015;11:251-63. 